\title{
CONTENTMENT AND AFFECT IN THE ESTIMATION OF HAPPINESS
}

Mariano Rojas and Ruut Veenhoven

Social Indicators Research, online since October 2011

Springer Science+Business Media B.V. 2011

DOI 10.1007/s11205-011-9952-0

\begin{abstract}
How do we assess how happy we are? One theory is that we compare life-as-it-is with standards of how-life-should-be. In this view, happiness emerges from a cognitive evaluation that draws on socially constructed standard of the good life. Another theory holds that we rather infer happiness on the basis of how well we feel most of the time. In that view, happiness is an unreasoned affective experience that roots in the gratification of universal human needs. One question that emerges from this discussion is whether these are really independent ways of evaluating life. If so, a next question is what their relative weight is in the evaluation. These questions are addressed at the nation level using data of the Gallup World Poll over the years 2006-2010. This survey in 127 nations involves not only a question on overall life satisfaction, but also a more cognitively focused question on how close one's life is to the best possible and a series of questions on yesterday's mood. Analysis of average scores in nations shows that mood and contentment are much intertwined, but also add to overall life satisfaction independently, the former more than the latter.
\end{abstract}

Keywords: Life evaluation, Subjective wellbeing, Cross-national Components of happiness, Life satisfaction, Contentment Affect

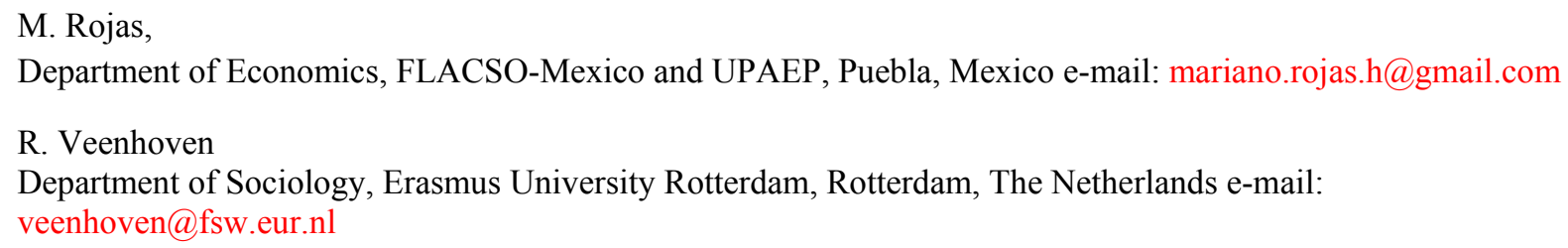




\section{INTRODUCTION}

Happiness is highly valued in present day society. Not only do people aim at happiness in their own life, but there is also support for the idea that we should care for the happiness of other people and that governments should aim at creating greater happiness for a greater number of citizens (Bentham 1789). This classic philosophy is not only more accepted these days, but also more practicable, now that scientific research provides more view on the conditions for happiness (Veenhoven 2010a).

In that context, happiness is commonly understood as a subjective appreciation of one's life as a whole. A central element in this definition is subjective 'appreciation' that is also referred to as 'evaluation', 'liking' and 'satisfaction'. These words refer to a state of mind, but leave some ambiguity about the precise nature of that state. It can be cognitive evaluation as well as affective experience.

Different theories of happiness stress diffe rent variants of appreciation. Comparison theory sees it as a cognitive judgment involving an estimate of the difference between actual and ideal life. Affect theory sees happiness rather as an estimate of how well one feels usually. The first author of this paper has elaborated the former view in his Conceptual referent-theory of happiness Rojas $(2005,2007)$ and Rojas and Vitterso $(2010)$ and the second author has elaborated on the latter view in his Need-theory of ha ppiness (Veenhoven 1991, 2009, 2010b).

This begs the question about the reality value of these theories. Do they apply at all, and if so, do they apply equally well or does one apply better than the other? Below we will first take a closer look at the concept of happiness and next review each of the above mentioned theories in more detail.

\subsection{Views on happiness}

What goes on in the mind when we assess how much we appreciate the life we live? A review of the various definitions reveals that some see that as a cognitive evaluation, while others see it as reading off affective experience.

\subsubsection{Cognitive definitions}

McDowell and Newell (1987: 204) describe life-satisfaction as a "Personal assessment of one's condition compared to an external reference standard or to one's aspirations". Likewise, Shin and Johnson (1978: 478) define life-satisfaction as a "global assessment of a person's quality of life according to his chosen criteria".

Some of the definitions in this line stress the active achievement of life goals (e.g. Annas 2004), while others rather stress the absence of unfulfilled aspirations, e.g. Schmittz (1930: 234) who depicted happiness as: a “".. state of being without desires". In all conceptualizations happiness is deemed to be higher, the smaller the gap between standard and reality.

\subsubsection{Affective definitions}

Several definitions depict happiness rather as an affective phenomenon. For instance Wessman and Ricks (1966: 240/1) wrote: "Happiness appears as an overall evaluation of the quality of the individual's own experience in the conduct of his vital affairs. As such, happiness represents a conception abstracted from the flux of affective life, indicating a decided balance or positive affectivity over long periods of time'". In a similar vein Fordyce (1972: 227) states "Happiness is a particular emotion. It is an overall evaluation made by the individual in accounting all his pleasant and unpleasant experiences in the recent past'. These definitions are close to Jeremy Bentham's (1789) famous definition of happiness as 
"'the sum of pleasures and pains", which also involves the notion of an 'affect balance'. A contemporary variation on this theme is proposed by Daniel Kahneman's (2000) in the notion of 'objective happiness', which is the 'raw' affective experience that underlies the overall evaluation of life.

\subsubsection{Mixed definitions}

Several definitions combine these two elements. For instance Diener defines 'Subjective Well-Being' (SWB) as being satisfied with life (cognition), while feeling good (affect) (Diener et al. 1997: 25). The two components are also involved in Chekola's (1974: 2002) definition of happiness as " ... realization of a life-plan and the absence of seriously felt dissatisfaction and an attitude of being displeased with or disliking one's life'. Likewise Sumner (1996: 145/6) describes 'being happy' as “ '... having a certain kind of positive attitude toward your life, which in the fullest form has both a cognitive and an affective component. The cognitive aspect of happiness consists in a positive evaluation of your life, a judgment that at least on balance; it measures up favorably against your standard or expectations... The affective side of happiness consists in what we commonly call a sense of well-being, finding your life enriching or rewarding or feeling satisfied or fulfilled by it'’.

\subsubsection{Veenhoven's conceptualization of 'Overall' Happiness and 'Components'}

In this line, Veenhoven (1984: 22-32) distinguishes between 'overall' happiness and 'components' of happiness assuming that the latter function as 'sub-totals' in the overall evaluation of life.

Overall happiness is defined as "the degree to which an individual judges the overall quality of his life-as-a-whole favorably'. Thus defined happiness appears as an attitude towards one's own life. This attitude is seen to draw on different sources of information, called 'components' of happiness. One source of information is estimates of how well we live up to standards of the good life and another source of information is how well we feel affectively.

Hedonic level of affect We experience different kinds of affects: feelings, emotions and moods and these experiences have different dimensions, such as active-inactive and pleasant-unpleasant. That latter dimension is called 'hedonic tone'. When we assess how well we feel we typically estimate the pleasantness in feelings, in emotions, as well as in moods. Veenhoven calls this 'hedonic level of affect' and this concept fits the above mentioned 'affective' definitions of happiness. This concept does not presume subjective awareness of that average level. One can feel good most of the time, without being fully aware of that. Therefore this concept can be applied to beings who cannot reflect on their own life, such as animals and little children.

Contentment Unlike animals and little children most adults can also evaluate their life with the use of reason and compare life-as-it-is with notions of how they want life-to-be. The degree to which an individual perceives his wants to be met is called 'contentment' by Veenhoven and this concept equals the above mentioned 'cognitive' definitions of happiness. This concept presupposes that the individual has developed some conscious wants and has formed an idea about their realization (Fig. 1).

\subsection{Theories of how we evaluate life}

These different definitions of happiness fit different theories about how we evaluate life, and these theories are typically part of a wider concept of man. 


\subsection{Cognitive theories}

Cognitive theories hold that happiness is a product of human thinking and as such roots in social constructions. Notions of how life should be are assumed to root in collective beliefs and to vary across cultures. Likewise, appraisals of how well life meets up to these standards are seen to be 'constructed' in the social discourse. This view on happiness is dominant in philosophy and also pervades the thinking of many social scientists.

\section{Comparison}

The theory assumes that we have 'standards' of the good life and that we constantly weigh the reality of our life against these standards. Different theories stress different standards. In the variant of life-time comparison the focus is on whether we are doing better or worse than before. In that view a happy youth will not add to happiness in adulthood. The social comparison variant stresses how well we are doing relative to other people, and in particular to people like us. In that view happiness is surpassing the Jones. Several of these theories are combined in Michalos'(1985) 'Multiple Discrepancies Theory' of happiness, which assumes that we not only compare with what we want and with what others have, but also with what we think we need and with what we deem fair.

\section{Social construction}

The idea that we compare to standards begs the question of where these standards come from. This is typically seen as an outcome of socialization, involving the adoption of collective notions of the good life, sometimes with minor modifications. These collective notions of the good life are seen as 'social constructions' that draw heavily on the wider culture and shared history. In this line some sociologists argue that happiness as such is also a social construction. In that view, happiness is a culturally variable concept, comparable to the notion of 'beauty'.

\section{Adjustment of standards}

Standards of comparison are presumed to be variable rather than fixed and to follow perceptions of possibilities. In other words: we would tend to judge life by what we think it can realistically be. Improvement of living conditions will therefore instigate higher aspirations and steady social progress is even believed to debouch in an 'inflation of aspirations'. In this view we are on a 'hedonic treadmill' (Brickman and Campbell 1971).

\section{Reflected appraisal}

A sociological variant holds that we not only compare our life to own standards, but that we also appraise our life through the eyes of others, in other words, that in assessing how happy we are, we estimate how happy other people think we are. If so, this enhances the salience of shared standards of the good life. This theory is summarized in Fig. 2.

\subsection{Affective Theories}

Affect theory holds that happiness is a reflection of how well we feel generally. In this view we do not 'calculate' happiness, but rather 'infer' it, the typical heuristic being "I feel good most of the time, hence I must be happy' (Schwarz and Strack 1991). In this line of thought, one question is how we take stock of our affective experience. Another question is what makes us feel good or bad and this links up to the wider question about the functions of affect.

\section{Frequency of affect}

It would seem that the overall evaluation of life is geared by the most salient affective experiences and that these are typically intense affects. This view is common in fiction and 
is more or less implied in life-reviews. In than line Bentham (1789) assumed that happiness comes from the sum of pleasures and pains weighted by intensity and duration. Yet research using the Experience Sampling Method shows that duration matters more than intensity, overall life-satisfaction being predicted by the relative frequency of positive to negative affect and not by the intensity of affects (Diener et al. 1991).

\section{Mood as informant}

How do we assess that relative frequency? The cognitive view on affect procession suggests that we compute an affect balance in some way, using estimates of how often we feel good or bad. A competing view is that this occurs automatically and that the balance reflects in mood. In this view mood is an affective meta-signal that, contrary to feelings and emotions, is not linked to specific objects. Emotions denote an affective reaction to something and prepare the organism to a response, while mood informs about the overall condition of the organism without preparing for specific action.

\section{Gratification of needs}

Why do we feel good or bad at all? Probably because that informs us about how well we are doing. Affects are an integral part of our adaptive repertoire and seem to be linked to the gratification of human needs. 'Needs' are vital requirements for functioning, such as eating, bonding and exercise. Nature seems to have safeguarded the gratification of these needs with affective signals such as hunger, love and zest. In this view, positive mood signals that all needs are sufficiently met at the moment.

'Needs' in this theory should not be equated with 'wants' in the above discussion of cognitive theories. Needs are inborn and universal while 'wants' are acquired and can be variable across cultures. Wants can concur more or less with needs.

\subsubsection{Motivation to Act}

In this view, negative and positive mood function as red and green lights on the human machine, indicating either that there is something wrong or that all systems are functioning properly. If so, this is likely to have behavioral consequences, negative mood urging to cautions and positive mood encouraging going on. This is what Fredrickson (2004) denotes as the 'broadening' effect of positive affect. This theory is summarized in Fig. 3.

\subsection{Research Questions}

How well do these conc epts and theories fit reality? Are cognitive and affective appraisals really different? Can we feel good most of the time, but still think of our life as substandard? Or can we think that we live the best possible life but still feel depressed?

Several scholars would deny that. Cognitive accounts of affective experience assume that we feel good because we com pare well (e.g. Oatley 1992). Reversely there are claims that cognitive comparison is driven by affective experience, for example that we select standards of comparison that make sense of how we feel (e.g. Wessman and Ricks 1966:110). In these views, cognition and affect are two sides of the same evaluative coin.

In this study we assess (1) to what extent cognitive and affective evaluations of life vary independently, if so, (2) whether their correlation to overall happiness differs, an if so (3) whether the cognitive component has more weight (as predicted by the first author) or the affective component (as predicted by the second author).

\subsection{Earlier Research}

Research findings on inter-correlation of the different kinds of happiness are gathered in the 
World Database of Happiness (Veenhoven 2011a). The collection 'Measures of Happiness' of that database (Veenhoven 2011b) involves a systematic classification of measures of happiness based on the above distinction between overall happiness (code $\mathrm{O}$ ), hedonic level of Affect (code A) and contentment (code C). Observed correlations between scores on measures of that kind are listed in the finding report 'Happiness: Correspondence of different measures' (Veenhoven 2011c) which contained near to 200 such findings in June 2011.

\section{Micro level}

Most of these findings concern correspondence of responses to questions about different kinds of happiness by the same individuals. Of these findings 7 are about similarity between scores on measures of hedonic level (A) and on measures of contentment (C). ${ }^{1}$ The average correlation is +0.45 . $^{2}$ A similar average $(+0.44)$ appears in 35 findings on correspondence between scores on measures of contentment $(\mathrm{C})$ and overall happiness $(\mathrm{O}){ }^{3}{ }^{3}$ Lastly 147 findings are about the correspondence between hedonic level of affect (A) and overall happiness $(\mathrm{O}){ }^{4}$ The average correlation is slightly larger in this case, $r=+0.48$. So no difference at first sight.

Yet, the correlation between scores on measures of hedonic level (A) and of overall happiness $(\mathrm{O})$ is probably an underestimation of the true correspondence of these happiness variants. One reason is that most measures of hedonic level are based on recent affective experience (last 2 week, today), which is more variable than satisfaction with life-as-awhole. A second reason is that the response format is quite different, most measures of hedonic level are multiple item affect balance scales while overall happiness is typically measured using single questions . Consequently we see a larger correlation in the eight studies that measured both hedonic level (A) and overall happiness $(\mathrm{O})$ with similar questions on how one generally feels; $r=+0.63$ in that case.

All these studies were done in western nations, and only half among general population samples. Unfortunately none of these 196 studies involved measures of all three happiness variants.

\section{Macro level}

Only one of the findings is at the macro level of nations and reports a correlation of +0.72 between life-satisfaction $(\mathrm{O})$ and affect-balance in 39 nations.

\section{Multi level}

One multi-level study that compared within-nation correlations at the micro level across nations at the macro level. Within person correlations between hedonic level (A) and overall life-satisfaction $(\mathrm{O})$ appeared to be stronger in individualistic nations than in collectivistic societies (Suh et al. 1998: 485-486).

\section{METHOD}

In this study we address the question at the macro level, comparing average scores on each of these three variants of ha ppiness in nations. We use data obtained in the Gallup World Polls over the years 2006-2010, which cover 127 nations (see "Appendix").

The Gallup W orld Poll draws on representative samples of the general public in countries. The sample size in each of the nations is about 1,000 persons. The program aims at repeated surveys over time and for that reason several countries are surveyed more than once between 2006 and 2010. In these cases we use average scores, which consequently draw on samples of 2000 or more. Since 2006 the core questionnaire involved questions on all three variants of happiness. 
This data set is unique in that it contains measures of all three happiness variants. Unfortunately it allows only analysis at the $m$ acro level of nations. One reason is that the micro data are not av ailable, at least not at a price we could pay. Another reason is that affective experience is $m$ easured using yester days mood, which does not reliably indicate how individuals typically feel.

\subsection{Variables}

The first Gallup World Poll in 2005 involved both a question on contentment and a series of questions on current affect. In 2006 a question on life-satisfaction was added. These questions read as follows:

\subsubsection{Overall Happiness: Question on Life Satisfaction (O-SL)}

All things considered, how satisfied are you with your life as a whole these days?

\section{0 dissatisfied}

10 satisfied

This question invites to a global evaluation of one's life and is therefore coded ' $\mathrm{O}$ ' for Overall happiness'. 5 Since the term 'satisfaction with life' is used the sub-code of this question is '-SL' from 'Satisfaction with Life'. This item is similar to the standard question on life satisfaction used in the World Values Survey. The only difference is in the range of response options, which is 1-10 in the World values Survey and 0-10 in this Gallup World Poll.

\subsubsection{Contentment: Question on Best-Worst Possible Life (C-BW)}

Here is ladder representing the 'ladder of life'. Let's suppose the top of the ladder represents the best possible life for you; and the bottom, the worst possible life for you. On which step of the ladder do you feel you personally stand at the present time?

10 best possible

\section{0 worst possible life}

In this question the focus is not on 'satisfaction' with life, but on how close life is to the 'best possible'. In other words, the question is about the gap between life-as-it-is and perceptions of how-life-could-be. As such, the question invites to a comparison with notions of ideal life and such notions root in collective representations rather than in personal experience. For these reasons this question is classified as tapping 'contentment'. ${ }^{6}$ This item is known as the 'Cantril ladder'. It was developed by Kilpatrick and Cantril (1960) and has since been used in several cross-national studies.

\subsubsection{Affect Balance: Questions On How One Felt Yesterday (A-AB)}

The Gallup World Poll also includes a battery of questions about mood in the previous day. These questions have a binary answer: 'yes' or 'no'.

Did you experience the following feelings during A LOT OF THE DAY yesterday? How about.

$$
\begin{aligned}
& \text { - Enjoyment? } \\
& \text { - Physical pain? } \\
& \text { - Worry? } \\
& \text { - Sadness? }
\end{aligned}
$$


$\begin{array}{ll}\text { - Stress? } & \text { (e) } \\ \text { - Anger? } & \text { (f) } \\ \text { - Depression? } & \text { (g) } \\ \text { - Love? } & \text { (h) }\end{array}$

Now please think about YESTERDAY, from the morning until the end of the day. Think of where you were, what you were doing and how you felt.

- Did you feel well rested yesterday?

- Did you smile or laugh a lot yesterday?

- Did you learn or do something interesting yesterday?

- Would you like to have more days just like yesterday?

- Were you proud of something you did yesterday?

- Were you treated with respect all day yesterday?

The focus on affective experience is not only in the wording of the questions, but also in the time frame. Reference to yesterday implies that the question is on effective experience and not on cognitive judgment of life.

From the responses we computed an affect balance score. To that end we first computed the percentage of 'yes' answers to the questions on positive affect in each nation. We summed the percentage yes answers to the questions $\mathrm{a}, \mathrm{h}, \mathrm{i}, \mathrm{j}, \mathrm{k}, \mathrm{l}, \mathrm{m}$ and $\mathrm{n}$ and divided that sum by 8 . Next we computed the percentage of yes answers to questions about negative affect $b, c, d, e, f, g$ and divided that sum by 6 . As a last step we subtracted the latter mean of negative affect from the former mean of positive affect.

This affect balance score does not measure hedonic level of affect of individual persons adequately, since yesterday's mood does not always correspond with how well one feels most of the time. Yet this battery can be used for measuring hedonic level in aggregates, such as nations, since individual variations balance out in big samples.

The focus of this measure is clearly on affective experience. It is therefore coded A of Affect with the sub-code AB of Affect Balance. ${ }^{7}$

\subsection{Pattern of Responses}

How are these questions answered in the various nations? Central tendencies are presented in Table 1. Life satisfaction ranges from 8.50 in Costa Rica to 2.62 in Togo while Contentment varies from 8.00 in Denmark to 3.24 in Togo. In all nations the percentage of positive feelings tends to be greater than the percentage of negative feelings and hence all scores on affect balance are positive. The highest score is observed in Latin American countries such as Panama, Venezuela, Paraguay and Costa Rica, as well as in Kenya, where the degree to which positive feelings outweigh negative feelings is above 60 percentage points. The lowest score is in Ethiopia with a positive balance of only 11 percentage points.

\subsection{Inter-Correlations}

Table 2 provides the correlation coefficients between the variables. It is observed for the zero-order correlations that there is a very high correlation between life satisfaction and contentment $(+0.85)$. The correlation between life satisfaction and affect is relatively lower, but still strong $(+0.51)$. It is also interesting to observe that contentment and affect balance are positively correlated $(+0.42)$ which means that feeling good and being contented with life tend to go together.

Contrary to common practice we do not report statistical significance, since this set of nations is not a probability sample. ${ }^{8}$ 
Our first research question was about the difference between cognitive and affective appraisals of life. If these are just two sides of the same coin, we can expect an almost perfect correlation between our measures of contentment and affect. If they represent different appraisals, there will also be correlation, since the same life is being judged, but less than perfect correlation.

In Table 2 we have seen that the zero-order correlation between average contentment and average affect balance in nations appears is considerable $(\mathrm{r}=+0.42)$, but far from perfect and clearly less than the correlation between contentment and overall lifesatisfaction. Why is the correlation not stronger? The scattergram on Fig. 4 provides some clues.

The first thing that catches the eye is that there is much dispersion, rather than a concentration around the regression line, we see a cloud.

A second noteworthy thing is that the cloud is not symmetric, we see quite some countries in the upper left section, but the right bottom section is empty. This means that high affect can co-exist with low contentment, but that low-affect and high contentment does not. ${ }^{9}$ This could mean that affective experience sets a bottom line.

\subsection{Consonant Clusters}

Affective experience and cognitive contentment go together in most of the countries. Beginning left at the bottom of Fig. 4, we see five countries where low affect is accompanied with low contentment. These countries are Georgia (GE), Haiti (HT), Ethiopia (ET), Sierra Leone (SL), and Armenia (AM), all cases of recent upheaval and facing very low socio-economic conditions.

In the middle of Fig. 4 are countries where medium affect goes together with medium contentment. In this section we see former communist countries such as Russia (RU) and Poland (PL) as well as China (CN) and South Africa (ZA).

In the upper right segment are some more Latin American nations, e.g. Mexico (MX), Costa Rica (CR) and Venezuela (VE), together with European nations, such as Denmark (DK), Norway (NO), Netherlands (NE), Finland (FE) and Sweden (SE) Ireland (IE) as well as Canada (CA).

\subsection{Deviant Clusters}

Let us now take a closer look at the deviations, since these denote independent variation in affective experience and cognitive contentment. Beginning at the top-left of Fig. 4 the first question is whether there is something common to the countries where low contentment goes together with high affect. These are typically African countries, such as Mali (ML), Kenya (KE), Malawi (MW), Niger (NE) and Ghana (GH).

Moving to the right in the top segment of Fig. 4 the next question is about the countries where high affect goes together with medium contentment. These are typically Latin American nations, such as Paraguay (PY), El Salvador (SV) and Panama (PA).

The last deviant cluster is in the middle of the bottom section of Fig. 4, where medium and high contentment goes together with low affect. These are typically situated in the Middle East, e.g. Yemen (YE), Azerbaijan (AZ), Palestine (PS) Iran (IR) and Lebanon (LB). A bit higher in this cluster are also former communist countries, such as Moldova 
(MD), and India (IN) and Pakistan (PK). Israel (IL) is a case of high contentment and relatively low affect.

The existence of these deviant cases supports the view that two components of happiness are not just two sides of the same coin, but involve different estimates that do not always concur. Moreover the existence of recognizable clusters in these cases shows that the observed deviations are no random fluctuations.

\section{ROLE OF AFFECT AND CONTENTMENT IN EXPLAINING LIFE} SATISFACTION

The second question is about the relative weight of these appraisals in the overall evaluation of life. Are these weights about equal? If not, does cognitive comparison dominate in line with Rojas' conceptual referent theory of happiness? Or does affect prevail as predicted by Veenhoven's need theory of happiness?

The zero-order correlations in Table 2 suggest a greater role of the cognitive component, the correlation between overall life-satisfaction and contentment being +0.85 , while the correlation between life-satisfaction and affect balance is +0.51 .

Partial correlation analysis also suggests that cognitive appraisals dominate. The partial correlation between life satisfaction and contentment is hardly reduced when affect balance is partialled out $(\mathrm{rp}=+0.81)$. On the other hand, the correlation between life satisfaction and affect balance is much reduced when contentment is controlled, $\mathrm{rp}=+0.31$. This picture is confirmed in a regression analysis. See Table 3.

Models 1 and 2 practically repeat the information presented in Table 2; they are introduced in Table 3 for comparison purposes. Model 1 depicts the explanatory power of affect on life satisfaction. An increase in the country's affective situation is accompanied by a raise in life satisfaction, and affect explains about $26 \%$ of the variability in life satisfaction. Model 2 studies the explanatory power of contentment on life satisfaction. The estimated coefficient is positive and large: on overage a raise of 1 standard deviation in contentment increases life satisfaction in 0.84 standard deviations. What is probably more relevant for our purpose, contentment alone explains about $71 \%$ of the variability in life satisfaction.

Model 3 incorporates both contentment and affect in the analysis. It is found that the coefficient of contentment does remain close to the one estimated in Model 2, while the coefficient of affect substantially declines with respect to the one estimated in Model 1. Furthermore, a comparison of Models 3 and 2 shows that affect plays a marginal role in explaining life satisfaction once contentment is taken into consideration (the $\mathrm{R}^{2}$ of Model 3 is only 0.03 higher than the $\mathrm{R}^{2}$ of Model 2 ). On the other hand, a comparison of Model 3 and Model 1 shows that the capacity of explaining life satisfaction triples when contentment is added to a model which already incorporates affect as an explanatory variable (The $\mathrm{R}^{2}$ raises from 0.26 to 0.74 ). These analyses suggest that in making an overall assessment of their life people's contentment substrate plays a larger role than their affective substrate.

\section{DISCUSSION}

\subsection{Difference Between Cognitive and Affective Evaluations of Life}

The first question was whether cognitive and affective assessments really differ. The data show that they are related, yet different. Though average scores go together in about half of 
countries, they diverge considerably in the other half of the cases. The data also show that there is system in the divergence.

The most notable finding is that there are no countries where people are contented in spite of feeling miserable, while there are quite some countries where people feel good, while being discontented. Apparently, affective experience dominates cognitive evaluation when affect is low. This suggests primacy of affect; comparable with Zajonc's (1984) observation that feeling precedes cognitive judgments. In this case that primacy seems to occur only when the balance of affect is close to zero. In terms of Veenhoven's need theory of happiness this would mean that affective signals get stronger relatively when need gratification approaches a critical minimum and overrule different cognitive appraisals in such cases.

The observed patterns of divergence can be interpreted in this context. The combination of high affect and low contentment in African countries can then be seen to mean that basic human needs are fairly well met in these societies, though living conditions fall short to western standards, which dominate views on the 'best possible life'. The same reasoning can apply to the Latin American nations, where western standards are likely to be more prominent. In this context the combination of low affect and medium contentment observed in the Middle East means that need gratification is poor in these societies, in spite of the fact that they do less bad with respect to meeting local standards of the good life. These regional differences are discussed in more detail in Brule' and Veenhoven (submitted).

\subsection{Relation with Overall Happiness}

Veenhoven's Need-theory holds that affective experience dominates the overall evaluation of life, while Rojas' Conceptual referent-theory predicts that cognitive evaluation will be more important. The data of this study support Rojas' view. Table 2 shows a stronger correlation between life-satisfaction and contentment than between life-satisfaction and affect balance, both in zero-order correlations and in partial correlations. Results from Table 3 do also corroborate this view; contentment has much greater power than affect balance in explaining the variability in life satisfaction across countries.

So it seems that people's comparisons to standards - which may have a social or cultural substrate-, have considerable importance when assessing their satisfaction with life. Goals and evaluation norms may differ across cultures and even across persons, and they may be socially influenced.

Still this is not the last word. An alternative explanation for the stronger correlation between life-satisfaction and contentment is that the questions used are quite similar. Firstly there is similarity in the content of the questions; many respondents may not have fully appreciated the difference between 'satisfaction with life' and closeness to the 'best possible life'. Secondly, the 0-10 numerical rating scales are identical. On the other hand, the measure used for assessing hedonic level of affect differs both in content and in response format.

These possible method effects cannot be tested as yet. Further research should apply more focused measures of contentment, for instance first having respondents list the main things they want from life and next have them rate how well these wants are met. ${ }^{10}$ The aim would be to have a measure of contentment with more texture and equally distinct from life satisfaction as the measure of affect used here. Such measures of contentment have been used at the individual level, but not yet at the nation level. Another option is to frame questions on all three variants of happiness in the same format, e.g. 'Please rate on this $0-10$ scale (a) how pleasant you feel most of the time, (b) how well you are doing in getting the 
things you want from life and (c) how satisfied you are with your life-as-a-whole these days'. In that context one could also ask respondents to what extent they agree with statements such as 'I am in good mood most of the time, though I am not very successful in getting what I want from life'.

\section{CONCLUSION}

Affective and cognitive appraisals of life do not always parallel. The evaluations differ in about half of the nations of the present day world and the most common divergent combination is high affect with low contentment. Cognitive evaluation seems to dominate in the overall evaluation of life.

Appendix

See Table 4. 


\section{REFERENCES}

Annas, J. (2004).

Happiness as achievement, Deadalus.

Journal of the American Academy of Arts and Science, 133, 44-51.

Bentham, J. (1789).

Introduction to the principles of morals and legislation.

London: Payne.

Brickman, P., \& Campbell, D. T. (1971).

Hedonic relativism and planning the good society.

In M. H. Appley (Ed.), Adaptation level theory (pp. 287-302). New York, USA: Academic Press. Brulé, G., \& Veenhoven, R. Affective and cognitive appraisals of life (submitted).

Chekola, M. G. (1974).

The concept of happiness.

PhD Dissertation, University of Michigan, Ann Arbor, USA.

Diener, E., Pavot, W., \& Sandvik, E. (1991).

Happiness is the frequency, not intensity, of positive versus negative affect.

In F. Strack, et al. (Eds.), Subjective well-being. Oxford, UK: Pergamon.

Diener, E., Suh, E., \& Oishi, S. (1997).

Recent findings on subjective well-being.

Indian Journal of Clinical Psychology, 24, 25-41.

Fordyce, M. W. (1972).

Happiness, its daily variation and its relation to values.

PhD Dissertation, U.S. International University, San Diego, California, USA.

Fredrickson, B. L. (2004).

The broaden-and-build theory of positive emotions.

Philosophical Transactions Biological Sciences, 359, 1367-1377.

Kahneman, D. (2000).

Experienced utility and objective happiness: a moment based approach.

In D.Kahneman \& A. Tverski (Eds.), Choices values and frames. New York: Cambridge University Press.

Kilpatrick, F. P., \& Cantril, H. (1960).

Self-anchoring scaling: A measure of individuals' unique reality worlds.

Journal of Individual Psychology, 16, 158-173.

McDowell, I., \& Newell, C. (1987).

Measuring health: A guide to rating scales and questionnaires.

New York: Oxford University Press.

Michalos, A. C. (1985).

Multiple discrepancies theory (MDT).

Social Indicators Research, 16, 347-413. 
Oatley, K. (1992).

Best laid schemes. The psychology of emotions.

Cambridge, UK: Cambridge University Press.

Rojas, M. (2005).

A conceptual-referent theory of happiness: heterogeneity and its consequences.

Social Indicators Research, 74(2), 261-294.

Rojas, M. (2007).

Heterogeneity in the relationship between income and happiness: A conceptual-referenttheory explanation.

Journal of Economic Psychology, 28, 1-14.

Rojas, M. \& Vitterso, J. (2010).

Conceptual referent for happiness: Cross-country comparisons.

Journal of Social Research \& Policy, 1, 103-116.

Schmittz, O. A. (1930).

Glück und Lebenskunst (happiness and the art of living).

Psychologische Rundschau, 2, 233-238.

Schwarz, N., \& Strack, F. (1991).

Evaluating one's life: A judgment model of subjective well-being.

In F. Strack, et al. (Eds.), Subjective well-being (pp. 27-47). Oxford, UK: Pergamon.

Shin, D., \& Johnson, D. M. (1978).

Avowed happiness as the overall assessment of the quality of life.

Social Indicators Research, 5, 475-492.

Suh, M. E., Diener, E., Oishi, S., \& Triandis, H. C. (1998).

The shifting basis of life satisfaction judgments across cultures: Emotions versus norms.

Journal of Personality ans Social Psychology, 74, 482-493.

Sumner, L. W. (1996).

Welfare, happiness and ethics.

New York: Oxford University Press.

Veenhoven, R. (1984).

Conditions of happiness.

Dordrecht, The Netherlands: Reidel (now Springer).

Veenhoven, R. (1991).

Is happiness relative?

Social Indicators Research, 24, 1-34.

Veenhoven, R. (2009).

How do we assess how happy we are?

In A. Dutt \& B. Radcliff (Eds.), Happiness, economics and politics, Edward Elger

Publishers, USA. 
Veenhoven, R. (2010a).

Greater happiness for a greater number: Is that possible and desirable?

Journal of Happiness Studies, 11, 605-629.

Veenhoven, R. (2010b).

How universal is happiness?

In E. Diener, J. F. Helliwell \& D. Kahneman (Eds.), International differences in well-being (Chapter 11, pp. 328-350). Oxford University Press, New York.

Veenhoven, R. (2011a).

World database of happiness: Continuous register of research on subjective enjoyment of life. Rotterdam: Erasmus University. Available at: http://worlddatabaseofhappiness.eur.nl.

Veenhoven, R. (2011b).

Collection measures of happiness. World database of happiness. Available at:

http://worlddatabaseofhappiness.eur.nl/hap_quer/hqi_fp.htm.

Veenhoven, R. (2011c).

Happiness: Correspondence of different measures. World database of happiness, collection of correlational findings, finding report H6. Assessed June, 2011 at: http://worlddatabase ofhappiness.eur.nl/hap_cor/top_sub.php?code=H6.

Wessman, A. E., \& Ricks, D. F. (1966).

Mood and personality.

New York, USA: Holt, Rinehart and Wilson.

Zajonc, R. B. (1984).

On the primacy of affect.

American Psychologist, 39, 117-123. 
Fig. 1 Happiness and its components

global assessment

sub-totals:

OVERALL HAPPINESS

Satisfaction with one's life-as-whole

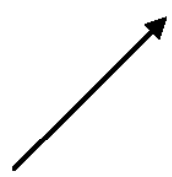

Hedonic level of affect

Balance of pleasant and

Unpleasant affect

Affective experience

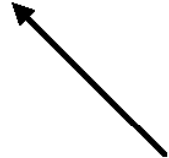

Contentment

Perceived realization

of wants 
Fig. 2 Cognitive theory of how happiness is assessed

global assessment

\section{OVERALL HAPPINESS}

Satisfaction with one's life-as-whole

sub-assessment:

\section{Contentment}

Perceived realization of wants

$$
\uparrow
$$

information basis

Cognitive comparison

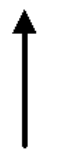

underlying process

Standard setting

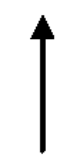


Fig. 3 Affect theory of how happiness is assessed

global assessment

sub-assessment:

information basis

underlying process

substrate

\section{OVERALL HAPPINESS}

Satisfaction with one's life-as-whole

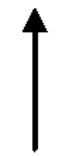

Hedonic level of affect

Balance of pleasant and unpleasant affect

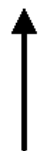

Affective experience

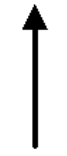

Need gratification

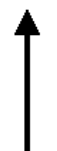

Human nature 
Fig. 4 Scatter plot of affect balance and contentment in 127 nations

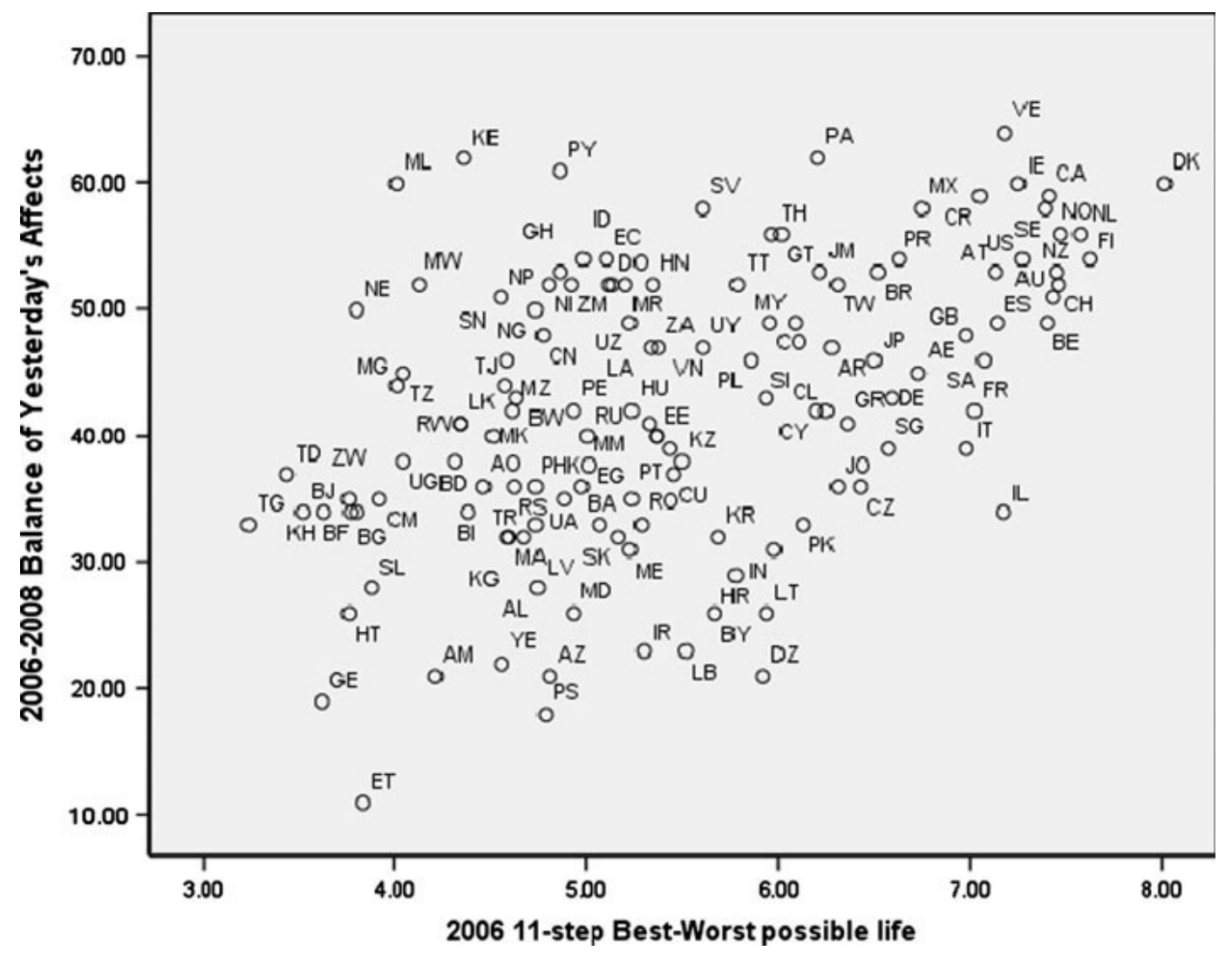


Table 1 Basic statistics for life satisfaction, contentment and affect balance

\begin{tabular}{|c|c|c|c|c|c|}
\hline & Mean & $\begin{array}{l}\text { Standard } \\
\text { deviation }\end{array}$ & $\begin{array}{l}\text { Coefficient of } \\
\text { variation }\end{array}$ & $\begin{array}{l}\text { Countries } \\
\text { with highest } \\
\text { values }\end{array}$ & $\begin{array}{l}\text { Countries with } \\
\text { lowest values }\end{array}$ \\
\hline Satisfaction & 5.91 & 1.30 & 0.22 & Costa Rica (8.50) & Zimbabwe (3.05) \\
\hline \multirow[t]{2}{*}{ O-SL } & & & & $\begin{array}{l}\text { Puerto Rico (8.32) } \\
\text { Denmark }(8.24)\end{array}$ & $\begin{array}{l}\text { Benin (3.02) } \\
\text { Burundi (2.94) }\end{array}$ \\
\hline & & & & $\begin{array}{l}\text { Switzerland (8.02) } \\
\text { Finland (7.89) }\end{array}$ & $\begin{array}{l}\text { Tanzania }(2.82) \\
\text { Togo }(2.62)\end{array}$ \\
\hline Contentment & 5.45 & 1.14 & 0.21 & Denmark (8.00) & Cambodia (3.63) \\
\hline \multirow[t]{2}{*}{ C-BW } & & & & $\begin{array}{l}\text { Finland (7.61) } \\
\text { Netherlands (7.56) }\end{array}$ & $\begin{array}{l}\text { Georgia (3.62) } \\
\text { Benin (3.52) }\end{array}$ \\
\hline & & & & $\begin{array}{l}\text { Norway }(7.46) \\
\text { Switzerland (7.45) }\end{array}$ & $\begin{array}{l}\text { Chad (3.44) } \\
\text { Togo (3.24) }\end{array}$ \\
\hline \multirow[t]{4}{*}{$\begin{array}{l}\text { Affect balance } \\
\text { A-AB }\end{array}$} & 42.9 & 11.6 & 0.27 & $\begin{array}{l}\text { Panama (64) } \\
\text { Venezuela } \\
(64)\end{array}$ & $\begin{array}{l}\text { Yemen (20) } \\
\text { Palestine (20) }\end{array}$ \\
\hline & & & & Paraguay (64) & Georgia (20) \\
\hline & & & & $\begin{array}{l}\text { Kenya (63) } \\
\text { Costa Rica (61) }\end{array}$ & $\begin{array}{l}\text { Armenia (18) } \\
\text { Azerbaijan (17) }\end{array}$ \\
\hline & & & & & Ethiopia (11) \\
\hline
\end{tabular}


Table 2 Correlation matrix: zero order (left bottom) and partial correlations (right top)

\begin{tabular}{|l|c|c|c|}
\hline & Life satisfaction & Contentment & Affect balance \\
\hline Life satisfaction & 1 & 0.81 & 0.31 \\
\hline Contentment & 0.85 & 1 & -0.02 \\
\hline Affect balance & 0.51 & 0.42 & 1 \\
\hline
\end{tabular}


Table 3 The role of contentment and affect in explaining life satisfaction: regression analyses

\begin{tabular}{|c|c|c|c|c|c|c|}
\hline & \multicolumn{2}{|l|}{ Model 1} & \multicolumn{2}{|l|}{ Model 2} & \multicolumn{2}{|l|}{ Model 3} \\
\hline & $\begin{array}{l}\text { Standardized } \\
\text { coefficient }\end{array}$ & Prob. $>_{t}$ & $\begin{array}{l}\text { Standardized } \\
\text { coefficient }\end{array}$ & Prob. $>_{t}$ & $\begin{array}{l}\text { Standardized } \\
\text { coefficients }\end{array}$ & Prob. $>_{t}$ \\
\hline Affect balance & 0.512 & 0.00 & & & 0.191 & 0.00 \\
\hline Contentment & & & 0.843 & 0.00 & 0.762 & 0.00 \\
\hline $\mathrm{R}^{2}$ & 0.263 & & 0.718 & & 0.740 & \\
\hline
\end{tabular}


Table 4 List of 127 countries/autonomous territories

\begin{tabular}{|c|c|c|c|}
\hline Albania & Ecuador & Lebanon & Saudi Arabia \\
\hline Algeria & Egypt & Lithuania & Senegal \\
\hline Angola & El Salvador & Macedonia & Serbia \\
\hline Argentina & Estonia & Madagascar & Sierra Leone \\
\hline Armenia & Ethiopia & Malawi & Singapore \\
\hline Australia & Finland & Malaysia & Slovak Republic \\
\hline Austria & France & Mali & Slovenia \\
\hline Azerbaijan & Georgia & Mauritania & South Africa \\
\hline Bangladesh & Germany & Mexico & Spain \\
\hline Belarus & Ghana & Moldova, Republic of & Sri Lanka \\
\hline Belgium & Greece & Montenegro & Sweden \\
\hline Benin & Guatemala & Morocco & Switzerland \\
\hline Bolivia & Haiti & Mozambique & Taiwan \\
\hline Bosnia and Herzegovina & Honduras & Nepal & Tajikistan \\
\hline Botswana & Hong Kong & Netherlands & Tanzania \\
\hline Brazil & Hungary & New Zealand & Thailand \\
\hline Bulgaria & India & Nicaragua & Togo \\
\hline Burkina Faso & Indonesia & Niger & Trinidad Tobago \\
\hline Burundi & Iran & Nigeria & Turkey \\
\hline Cambodia & Ireland & Norway & Uganda \\
\hline Cameroon & Israel & Pakistan & Ukraine \\
\hline Canada & Italy & Palestine & United Arab \\
\hline Chad & Jamaica & Panama & United Kingdom \\
\hline Chile & Japan & Paraguay & United States \\
\hline China & Jordan & Peru & Uruguay \\
\hline Colombia & Kazakhstan & Philippines & Uzbekistan \\
\hline Costa Rica & Kenya & Poland & Venezuela \\
\hline Croatia & Korea, Republic of & Portugal & Vietnam \\
\hline Cyprus & Kuwait & Puerto Rico & Yemen \\
\hline Czech Republic & Kyrgyzstan & Romania & Zambia \\
\hline Denmark & Laos & Russian Federation & Zimbabwe \\
\hline Dominican Republic & Latvia & Rwanda & \\
\hline
\end{tabular}




\section{NOTES}

1 Veenhoven (2011c): section H6.2.3.

2 Four of these studies measured hedonic level using Affect Balance Scales (type A-AB) and contentment using the Cantril ladder (type C-BW). The average correlation is ?0.52. Two more studies used an Affect Balance Scale for measuring hedonic level but measured contentment using responses to questions about perceived realization of wants (type C$\mathrm{RW})$. The average correlation is ?0.40 in this case. One more study measured hedonic level using average daily mood over 6 weeks as reported in a dairy (type A-ARE) and measured contentment with the Cantril ladder (type C-BW). The correlation was only ?0.26.

3 Veenhoven (2011c), section H6.1.3.

4 Veenhoven (2011c), section H61.2.

5 The full classification of this question in the World Database of Happiness' collection of 'Happiness Measures' is O-SLW/c/sq/n/11/a.

6 The full classification of this question in the World Database of Happiness' collection of 'Happiness Measures' is C-BW/c/sq/1/11/a.

7 The ful 1 code of this indicator in th e World Database of Happiness' collection of 'Happiness Measures' is: $\mathrm{A}-\mathrm{AB} / \mathrm{yd} / \mathrm{mq} / 2 / \mathrm{a}$.

8 Test for statistical significance infor $\mathrm{m}$ us about the chan ce that a pattern observ ed in a probability sample also exists in th e population from which that sam ple was drawn. This dataset covers alm ost all count ries of the present $\mathrm{W}$ orld and therefore we can take the observed correlations for what they are.

9 This is not to say that this combination never occurs at the micro level of individuals.

10 Measure code C-RG/cm/mq/v/4/a in the collection 'Measures of Happiness' of the World Database of Happiness. 